\title{
Effects of dietary energy density and L-carnitine supplementation on growth performance, carcass traits and blood parameters of broiler chickens
}

\author{
M. Corduk ${ }^{1 \#}$, N. Ceylan' and F. Ildiz ${ }^{2}$ \\ ${ }^{1}$ Ankara University, Faculty of Agriculture, Department of Animal Science, 061 10, Ankara, Turkey \\ ${ }^{2}$ Turkish Atomic Energy Authority, Saraykoy Nuclear Research and Education Centre, Ankara,Turkey
}

\begin{abstract}
The present study was conducted to determine the effects of dietary metabolisable energy (ME) density and L-carnitine supplementation on the performance, carcass traits and blood parameters of broiler chickens. The experiment was designed with three levels of dietary energy (low, medium and high) and two levels of L-carnitine ( 0 and $100 \mathrm{mg} / \mathrm{kg}$ diet) in a $3 \times 2$ factorial arrangement. L-carnitine supplementation did not significantly affect body weight gain (BWG), feed intake (FI) and feed conversion ratio (FCR). However, FCR and BWG showed a significant improvement as dietary energy density increased. No significant interactions were observed between energy density and L-carnitine supplementation in the performance and carcass parameters studied in the study. Carcass yield and proportion of carcass sections were not affected significantly by any of the treatments. Chemical composition of the leg (thigh and drumstick) and breast muscle was not significantly influenced by dietary energy or carnitine, with the exception of the dry matter (DM) content of breast muscle. A low ME diet caused a significant increase in the DM content of chicken breast muscle. Furthermore, blood parameters did not show any differences between treatments. However, aspartate aminotransferase (AST) activity in blood was elevated in chickens fed a high ME diet compared to those on a low ME diet. The results of the investigation showed that Lcarnitine supplementation produced no significant improvement in broiler performance and meat quality. Higher levels of diet ME increased broiler performance, though no significant interactions could be found between energy and carnitine levels.
\end{abstract}

Keywords: Broiler, L-carnitine, metabolisable energy, growth, carcass quality, blood parameter

${ }^{\#}$ Corresponding author. E-mail: corduk@agri.ankara.edu.tr

\section{Introduction}

L-carnitine ( $\beta$-hydroxy $\gamma$-trimethylaminobutyrate) is a water-soluble quaternary amine that occurs naturally in microorganisms, plants and animals (Bremer, 1983). It is biosynthesized in vivo from lysine and methionine (Rebouche \& Paulson, 1986a) in the presence of ferrous ions and the vitamins, ascorbate, niacin and pyridoxine. These vitamins are required as co-factors for the enzymes involved in the metabolic pathway of L-carnitine (Rebouche \& Paulson, 1986b; Feller \& Rudman, 1988; Rebouche, 1991; Baumgartner \& Blum, 1993). It has been reported that L-carnitine has two major functions. The best known is to facilitate the transport of long-chain fatty acids across the inner mitochondrial membrane. L-carnitine also facilitates the removal of short- and medium-chain fatty acids from the mitochondria that accumulate as a result of normal and abnormal metabolism (Rabie et al., 1997a; Rabie \& Szilagyi, 1998; Matalliotakis et al., 2000; Buyse et al., 2001; Xu et al., 2003). Thus, dietary L-carnitine supplementation promotes the $\beta$-oxidation of these fatty acids in order to generate adenosine triphosphate (ATP) energy and improve energy utilisation (Rabie et al., 1997b; Neuman et al., 2002). Consequently, L-carnitine supplementation in diets reduces the amount of long-chain fatty acids availability for esterification to triacylglycerols and storage in the adipose tissue (Barker \& Sell, 1994; Xu et al., 2003). In addition, L-carnitine has secondary functions, including the containment, buffering and removal of potentially toxic acyl groups from cells, equilibrating the ratio of free $\mathrm{CoA}$ and acetyl-CoA between the mitochondria and cytoplasm, participating in biological processes such as regulation of gluconeogenesis, stimulating fatty acid and the metabolism of ketones, branched-chain amino acids, triglycerides and cholesterol (Novotny, 1998).

There are few published studies concerned with the use of different levels of energy density and L-carnitine in diets and their effects on the performance, carcass traits and blood parameters of broiler 
chickens. The effect of L-carnitine supplementation in broiler diets at different energy levels is less clear. Studies with broiler chickens have shown that supplemental dietary L-carnitine increased body weight gain (BWG), improved feed conversion ratio (FCR) and reduced abdominal fat content in broiler chickens (Rabie et al., 1997a; b; Rabie \& Szilagyi, 1998). However, there are contradictory results on which dietary L-carnitine supplementation did not affect growth performance, abdominal fat content and some internal organ weights (Cartwright, 1986; Barker \& Sell, 1994; Leibetseder, 1995).

In this study the aim was to evaluate the effects of energy density and L-carnitine supplementation in maize-soyabean meal based diets on the performance, carcass traits and some blood parameters of broiler chickens.

\section{Materials and Methods}

Three hundred and sixty one-day old Ross-308 broiler chickens with similar mean weights (45.47 $\pm 0.86 \mathrm{~g}$ ) were randomly allocated to six dietary treatments. Each treatment had six replicates with 10 birds $(5$ male +5 female $)$ per battery cage $(90 \times 85 \mathrm{~cm})$. Each cage was equipped with nipple drinkers and one feeder. Experimental diets (in mash form) and water were provided ad libitum. House temperature was maintained at $33-31{ }^{\circ} \mathrm{C}$ for week 1 and $31-29^{\circ} \mathrm{C}$ for two weeks. For the remainder of the experiment the temperature fluctuated with ambient temperature $\left(07: 00: 25-26{ }^{\circ} \mathrm{C} ; 13: 30: 32-33{ }^{\circ} \mathrm{C} ; 16: 00: 33-34{ }^{\circ} \mathrm{C}\right.$; 21:00: $27-28^{\circ} \mathrm{C}$ ). Continuous lighting was maintained. On day 14 all birds were vaccinated against Gumboro disease.

The experiment was conducted using a $3 \times 2$ factorial design with three levels of metabolisable energy (ME) $(12.55,12.97$ and $13.39 \mathrm{MJ} / \mathrm{kg}$ for starter diets; $12.97,13.39$ and $13.80 \mathrm{MJ} / \mathrm{kg}$ for grower diets) and two levels of dietary L-carnitine $\left(0\right.$ and $100 \mathrm{mg} / \mathrm{kg}$ in both starter and grower diets) in the form of Carniking ${ }^{(\mathbb{R})}$ (LONZA Ltd., Basel, Switzerland). L-carnitine was incorporated into the diets by replacing maize. Ingredients and the chemical composition of the basal diets are presented in Table 1. The diets consisted of maize, wheat, soyabean meal, fish meal, sunflower oil and DL-methionine and L-lysine HCL crystalline amino acids. The diets were formulated to be lower, to meet or to exceed NRC (1994) recommendations for broiler chickens. The low, medium and high ME diets had identical levels of crude protein (CP) (230 and $200 \mathrm{~g} / \mathrm{kg}$ for starter and grower diets, respectively). Prior to the formulation of the experimental diet, feed ingredients were analyzed for their DM, CP, crude fat (CF), starch and total sugar content, according to AOAC methods (1984). The ME of feed ingredients was calculated based on analyzed values of the feedstuffs (WPSA, 1989). The L-carnitine content of these basal diets was calculated based on the L-carnitine concentrations in the ingredients used (Harmeyer et al., 1998).

Chicken responses to dietary energy and L-carnitine were evaluated from 0 to 3 weeks (broiler starter period) and from 4 to 6 weeks (broiler growth period). Body weight gain, feed intake (FI) and FCR were calculated at three and six weeks of age. Mortality was recorded daily and dead birds were weighed to correct feed intake data. At the end of the experiment four birds ( 2 males +2 females) from each cage (total 24 for each treatment) were selected randomly from birds with a mass within one-half standard deviation of the mean cage weight. Each bird was weighed and leg-banded for identification. The jugular vein was cut and the birds were bled. At this time a serum sample was taken. They were then slaughtered and dissected by a trained team (Izah et al., 1990). The abdominal fat pad was dissected and weighed. Hot carcass yield, and legs and breasts (with bone and skin) were weighed. Carcass yield, abdominal fat, leg and breast as a proportion of individual body weights (BW) were calculated. Twenty-four left legs and breasts from each treatment were frozen immediately at $-4{ }^{\circ} \mathrm{C}$. The meat was separated manually from the bone and then homogenized using a blender with horizontal blades. Samples were then frozen and stored in a freezer at $-20^{\circ} \mathrm{C}$. These samples were analysed for DM, protein and fat using standard methods outlined by AOAC (1984). Serum samples were analyzed for glucose, blood urea nitrogen (BUN), creatinine, cholesterol, aspartate aminotransferase (AST; EC 2.6.1.1) and triglyceride, using commercial analytical kits (Sigma) and an autoanalyser (Hitachi Ltd, Tokyo).

The data obtained from the experiment were analysed statistically using the general linear model (GLM) procedure in the statistical software SPSSWIN (1994). Significant differences between treatment means were determined using Duncan's Multiple Range Test (5\% probability or error; Duncan, 1955). 
Table 1 Ingredients and chemical composition of the basal diets $(\mathrm{g} / \mathrm{kg})$

\begin{tabular}{lcccccc}
\hline & \multicolumn{5}{c}{ Broiler diet (g/kg) } \\
\cline { 2 - 7 } & \multicolumn{5}{c}{ Starter (0-3 weeks) } & \multicolumn{3}{c}{ Grower-Finisher (3-6 weeks) } \\
\cline { 2 - 7 } & $\begin{array}{c}\text { LowME } \\
\left(\mathrm{T}_{1}\right)^{*}\end{array}$ & $\begin{array}{c}\text { MediumME } \\
\left(\mathrm{T}_{3}\right)^{*}\end{array}$ & $\begin{array}{c}\text { HighME } \\
\left(\mathrm{T}_{5}\right)^{*}\end{array}$ & $\begin{array}{c}\text { LowME } \\
\left(\mathrm{T}_{1}\right)^{*}\end{array}$ & $\begin{array}{c}\text { MediumME } \\
\left(\mathrm{T}_{3}\right)^{*}\end{array}$ & $\begin{array}{c}\text { HighME } \\
\left(\mathrm{T}_{5}\right)^{*}\end{array}$ \\
\hline Ingredients & & & & & & \\
Maize & 460.78 & 438.98 & 413.23 & 495.27 & 473.49 & 451.69 \\
Wheat & 100.00 & 100.00 & 100.00 & 100.00 & 100.00 & 100.00 \\
Soyabean meal, 45\% CP & 338.66 & 342.30 & 350.00 & 322.37 & 326.00 & 329.64 \\
Fish meal & 40.00 & 40.00 & 40.00 & - & - & - \\
Sunflower oil & 29.95 & 48.13 & 66.74 & 44.30 & 62.48 & 80.66 \\
Limestone & 10.04 & 9.99 & 10.60 & 13.57 & 13.52 & 13.47 \\
Dicalcium phosphate & 11.00 & 11.06 & 9.99 & 14.02 & 14.08 & 14.15 \\
Salt & 3.50 & 3.50 & 3.50 & 3.50 & 3.50 & 3.50 \\
Vitamin premix & 2.50 & 2.50 & 2.50 & 2.50 & 2.50 & 2.50 \\
Mineral premix ${ }^{2}$ & 1.00 & 1.00 & 1.00 & 1.00 & 1.00 & 1.00 \\
DL-Methionine & 2.42 & 2.45 & 2.44 & 2.38 & 2.41 & 2.43 \\
L-Lysine HCL & 0.15 & 0.09 & - & 1.09 & 1.02 & 0.96 \\
& & & & & & \\
Total & 1000.00 & 1000.00 & 1000.00 & 1000.00 & 1000.00 & 1000.00 \\
Composition (calculated) & & & & & & \\
Dry matter (analysed) & 889.4 & 891.5 & 893.3 & 894.8 & 895.1 & 892.3 \\
Crude protein (analysed) & 229.6 & 231.5 & 233.1 & 203.5 & 204.1 & 201.8 \\
Crude fat (analysed) & 62.6 & 80.0 & 97.8 & 75.8 & 93.1 & 110.5 \\
ME (MJ/kg) & 12.55 & 12.97 & 13.39 & 12.97 & 13.39 & 13.80 \\
Calcium & 10.0 & 10.0 & 10.0 & 9.50 & 9.50 & 9.50 \\
Phosphorus (total) & 7.49 & 7.47 & 7.26 & 6.55 & 6.53 & 6.51 \\
Phosphorus (available) & 4.70 & 4.70 & 4.60 & 3.80 & 3.80 & 3.80 \\
Methionine & 6.10 & 6.10 & 6.10 & 5.30 & 5.30 & 5.30 \\
Met.+Cys. & 9.60 & 9.60 & 9.60 & 8.50 & 8.50 & 8.50 \\
Lysine & 13.20 & 13.20 & 13.30 & 11.50 & 11.50 & 11.50 \\
L-carnitine (mg/kg) & 11.48 & 11.43 & 11.42 & 7.81 & 7.76 & 7.70 \\
& & & & &
\end{tabular}

\footnotetext{
'Nutritional constituents per $\mathrm{kg}$ of diet: $3.6 \mathrm{mg}$ vitamin $\mathrm{A}$ (all-trans-retinol); $0.038 \mathrm{mg}$ vitamin $\mathrm{D}$ (cholecalciferol); $50 \mathrm{mg}$ vitamin $\mathrm{E} ; 5 \mathrm{mg}$ vitamin $\mathrm{K}_{3} ; 3 \mathrm{mg}$ vitamin $\mathrm{B}_{1} ; 6 \mathrm{mg}$ vitamin $\mathrm{B}_{2} ; 5 \mathrm{mg}$ vitamin $\mathrm{B}_{6} ; 0.030 \mathrm{mg}$ vitamin $\mathrm{B}_{12}$; $25 \mathrm{mg}$ niacin; $12 \mathrm{mg}$ Ca-D-pantothenate; $1 \mathrm{mg}$ folic acid; $0.05 \mathrm{mg}$ D-biotin; $400 \mathrm{mg}$ choline chloride; $2.5 \mathrm{mg}$ apo-carotenoic acid ethyl ester

${ }^{2}$ Nutritional constituents per kg of diet: $80 \mathrm{mg} \mathrm{Mn} ; 30 \mathrm{mg} \mathrm{Fe} ; 60 \mathrm{mg} \mathrm{Zn} ; 5 \mathrm{mg} \mathrm{Cu} ; 2 \mathrm{mg} \mathrm{I} ; 0.5 \mathrm{mg} \mathrm{Co} ; 0.15 \mathrm{mg} \mathrm{Se}$ *T1 - Low metabolisable energy (ME) without L-carnitine; T2 - Low ME with L-carnitine $(100 \mathrm{mg} / \mathrm{kg})$; T3 - Medium ME without L-carnitine; T4 - Medium ME with L-carnitine $(100 \mathrm{mg} / \mathrm{kg})$; T5 - High ME without Lcarnitine; T6 - High ME with L-carnitine $(100 \mathrm{mg} / \mathrm{kg})$
}

\section{Results and Discussion}

Performance data are presented in Table 2. The levels of dietary ME affected both BWG and FCR significantly throughout the experiment. The chickens on the high ME diet had a higher $(P<0.05)$ BWG from 0 to 3 weeks of age than those on the medium ME diet. Likewise, those chickens on the high ME diet showed a higher $(\mathrm{P}<0.05)$ increase in BWG during the experimental period from 4 to 6 and from 0 to 6 weeks of age compared with those on the low and medium ME diets. However, FI was not significantly influenced by dietary treatments. During the starter-period the high ME diet improved $(P<0.05)$ FCR compared with medium or low ME diets. The FCR of broiler chickens during the growth period was improved $(\mathrm{P}<0.05)$ by the high and medium ME diets. The FCR of broiler chickens during all periods $(0-6$ weeks) was improved by increasing energy density of the diet. There was no interaction between energy density and L-carnitine level of diets in terms of BWG, FI and FCR $(P>0.05)$. Mean mortality rate was similar for both main factors (between $1-2 \%$ ) and did not differ between dietary treatments. 


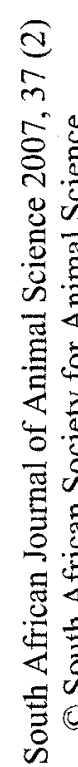

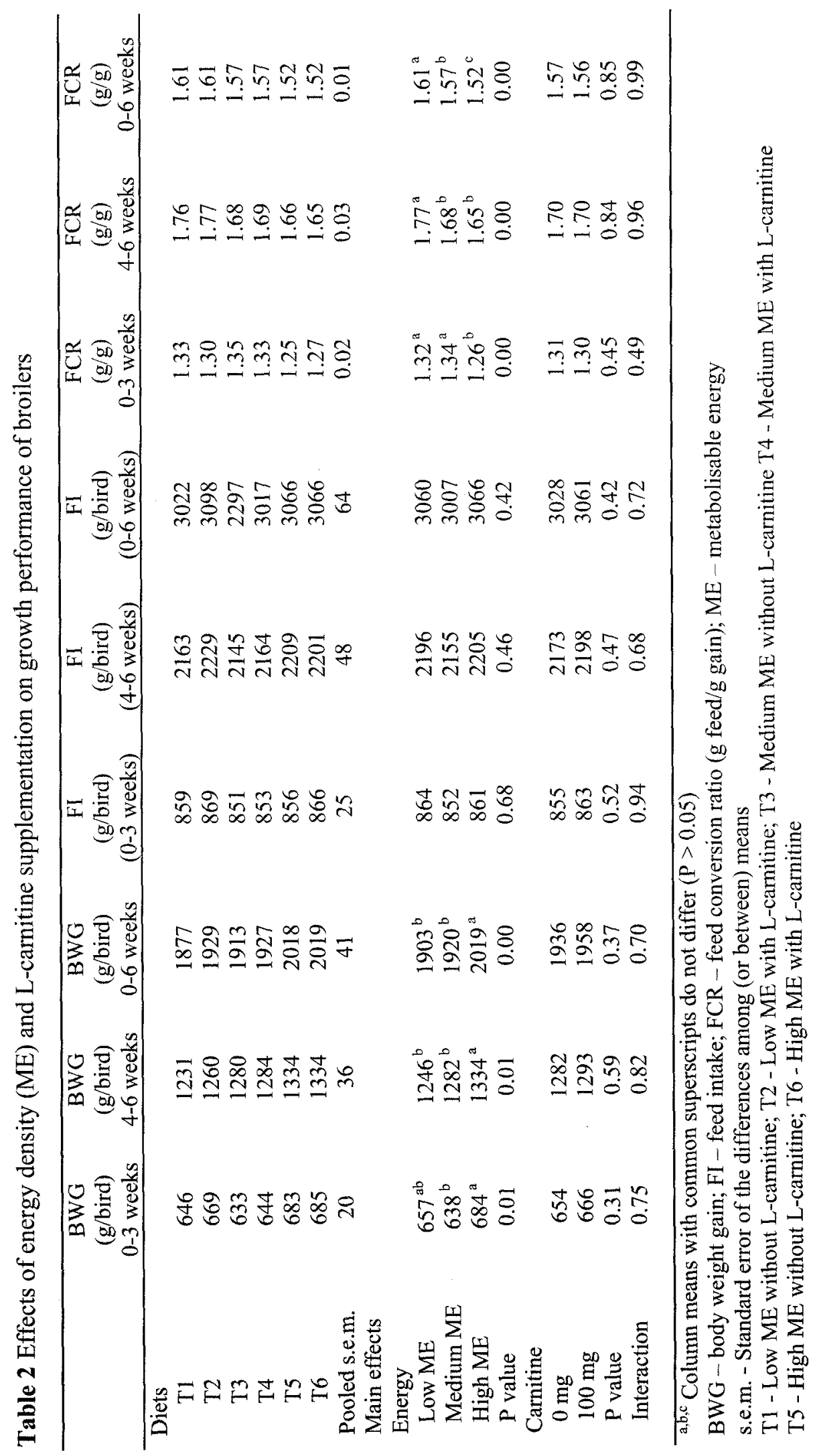

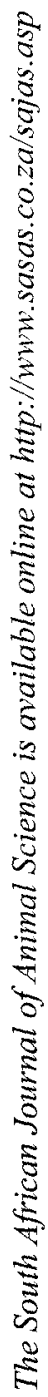


Table 3 shows the effects of energy density and L-carnitine supplementation on carcass traits, the chemical composition of the muscle and some blood parameters of the chickens. Dietary ME density and L-carnitine supplementation had no significant effect on the serum glucose, BUN, cholesterol, triglyceride and creatinine concentrations of the chickens. Feeding a diet with a high energy level significantly increased AST activity compared to broilers on a low energy diet. Neither dietary energy nor L-carnitine supplementation had significant effects on carcass yield, abdominal fat, leg and breast yield. With the exception of DM content of breast muscle, the chemical composition of leg and breast muscle was not influenced by dietary energy and carnitine levels. Feeding a diet with a low ME content significantly increased DM content of breast muscle. There was no interaction between energy density and L-carnitine level in terms of carcass traits, chemical composition of the muscle and some blood parameters of the broilers. Regardless of dietary L-carnitine supplementation, dietary energy levels had a significant effect on BWG and FCR during all feeding periods. Findings in the present study concurred with those of Rabie \& Szilagyi (1998) who reported that the feeding with a high ME diet significantly improved BWG and FCR of broiler chickens compared to broilers fed medium or low ME diets. Skinner et al. (1993) indicated that broilers fed high ME diets showed better FCR than those fed lower energy diets. However, they also reported that abrupt changes in diet energy density did not cause any significant impairment in FI and BWG when compared to a high ME diet. This may be because broilers are able to compensate their feed intake according to the energy density of the diet. Thus, similar weight gain should be maintained over a range of dietary energy levels. However, the low and medium dietary ME levels in this investigation caused significantly lower BWG at slaughter age than the high dietary ME treatment. The birds that received low ME diets may not have been able to adjust their feed intake because of high daily ambient temperatures during the study period. Fast growing broilers produce more heat and have greater difficulty in dissipating heat in hot temperatures (Cahaner \& Leensta, 1992; Eberhart \& Washburn, 1993; Yalçın et al., 1997), which leads to higher body temperatures (Cahaner et al., 1993) and reduced performance.

In the current study, dietary L-carnitine supplementation or ME and L-carnitine interaction did not significantly affect broiler performance. Although the basic carnitine level was low, and in spite of differences in ME supplied, no effect of supplemented carnitine was detected. Our results demonstrated that carnitine is not linked to energy utilization. Likewise, Rodehutscord et al. (2002) showed that carnitine supplementation is not linked to energy or protein utilization. Buyse et al. (2001) pointed out that performance data is not the only criteria from which the effectiveness of carnitine as a feed supplement should be evaluated. They found that chickens had clevated heart weights due to carnitine supplementation and expected these animals to be less sensitive to metabolic diseases. Lien \& Horng (2001) demonstrated that differences in serum triacylglycerols and nonesterified fatty acids as well as differences in hepatic carnitine palmitoyl transferase activity in broiler chickens fed L-carnitine supplemented diets can be uncoupled from growth and feed conversion data. Dietary L-carnitine supplementation or dietary ME levels did not significantly affect FI. Our FI results are in agreement with those of other researchers who used L-carnitine at levels of up to $500 \mathrm{mg} / \mathrm{kg}$ in broiler diets (Cartwright, 1986; Barker \& Sell, 1994; Leibetseder, 1995; Rabie \& Szilagyi, 1998; Buyse et al., 2001; Lien \& Horng, 2001; Rodehutscord et al., 2002; Xu et al., 2003). Carnitine in diets of growing broilers should probably be included at higher levels than in the present study, especially in light of the limited intestinal absorptive capacity of carnitine and its considerable microbial degradation in the intestine (Xu et al., 2003). However, Lettner et al. (1992) demonstrated that L-carnitine supplementation from 20 to $60 \mathrm{mg} / \mathrm{kg}$ in broiler diets tended to improve growth performance. Rabie et al. (1997b) indicated that the supplementation of dietary L-carnitine at levels of 50,100 or 150 $\mathrm{mg} / \mathrm{kg}$ in the basal diet significantly increased BWG of broiler chickens compared to those of broilers fed the basal diet. It is well established that L-carnitine plays an important role in the mitochondrial oxidation of long-chain fatty acid in the production of energy. In this instance the energy supply available to stimulate protein deposition may increase and thus, promote growth. The discrepancies between studies may result from different levels of L-carnitine supplementation, basic carnitine levels in the raw ingredients, the supply or absence of essential amino acids, (Rodehutscord et al., 2002), the possible effects of enzymatic breakdown of branched-chain amino acids (Owen et al., 2001), sparing effects of carnitine with regard to its precursors (lysine and methionine), limited intestinal absorptive capacity of carnitine and its considerable 
microbial degradation in the intestine (Xu et al., 2003), interspecies differences, age, sex, feeding programme, and the managerial or environmental conditions (Celik \& Ozturkcan, 2003) of the animals.

There was no significant interaction between ME and L-carnitine levels. L-carnitine supplementation did not influence any of the performance parameters examined in the current study in response to dietary ME level. Neither dietary L-carnitine supplementation, nor dietary ME level significantly affected the serum glucose, BUN, cholesterol, triglyceride and creatinine concentrations in broiler chickens (Table 3). It did influence AST activity. Findings in this study are consistent with Arslan et al. (2004) who reported L-carnitine administration via drinking water did not influence serum total cholesterol, total lipid and triglyceride of Japanese quail. However, they did find that L-carnitine supplementation significantly increased serum glucose level compared with a control group. Plasma AST activity may reflect changes in hepatic function in addition to alterations in muscle membrane permeability (Coles, 1986). External factors such as heat, trauma, infection, toxin and exercises can lead to increased free radicals and other reactive oxygen species (ROS) (Elstner, 1991; Halliwell et al., 1992). ROSs, including hydrogen peroxide, superoxide and hydroxyl, have the potential to induce considerable cell deaths via lipid peroxidation (Halliwell \& Gutteridge, 1990). The broiler chickens fed diets with high ME levels ingested higher levels of carbohydrate and fat than those of broilers receiving diets with low or normal ME levels. No significant effect of energy density on feed intake was determined. As a result, high heat stress can stimulate ROS production. These agents may cause lipid peroxidation in the membrane of the cell, resulting in tissue injury to organs, including the lungs, heart and liver. The increase in the AST activity is an indicator of a progressive liver cell injury followed by the increased production of ROS resulting in the induction of a chain of oxidative reactions in the liver and other organs (Arab et al., 2006). L-carnitine supplementation or dietary ME level did not significantly affect carcass yield and abdominal fat content. This may be due to the experiment being conducted in summer. High ambient temperatures may have limited the heat production of the broilers in order to prevent heat stress and inhibit fatty acid $\beta$-oxidation. The fatty acid $\beta$-oxidation rate may have prevented the carnitine supplement from significantly affecting the weight of the abdominal fat pad (Lien \& Horng, 2001). The findings in this study concur with those of other researchers who supplemented their experimental diets with from 50 to $500 \mathrm{mg} \mathrm{L}$-carnitine $/ \mathrm{kg}$ (Cartwright, 1986; Barker \& Sell, 1994; Leibetseder, 1995; Rabie et al., 1997a; b; Daskiran \& Teeter, 2001; Lien \& Horng, 2001; Celik et al., 2003). However, Lettner et al. (1992) found that the composition of the abdominal fat weight was significantly influenced by the addition of L-carnitine to the diet. Rabie et al. (1997a, b), Rabie \& Szilagyi (1998) and $\mathrm{Xu}$ et al. (2003) reported that the quantity and percentage of abdominal fat was significantly reduced by the addition of L-carnitine to broiler diets. L-carnitine could reduce the deposit of subcutaneous fat by decreasing the total activity of enzymes (glucose-6-phosphate dehydrogenase, malic dehydrogenase, isocitrate dehydrogenase, and lipoprotein lipase) in this tissue (Xu et al., 2003).

Supplementing the diets of broiler chickens from the age of 0 to 42 days with L-carnitine or feeding different dietary levels of ME did not significantly affect protein, fat and DM contents of leg muscle or the protein and fat content of breast muscle. However, the diet with a low ME level significantly increased the DM content of the breast muscle of the broilers. The results of the present study are in agreement with those reported by other authors who used L-carnitine at levels of $50-500 \mathrm{mg} / \mathrm{kg}$ in broiler diets (Barker \& Sell, 1994; Rabie et al. 1997b; Rabie \& Szilagyi, 1998). In contrast, Xu et al. (2003) showed that the fat content in breast muscle of male broilers was significantly increased when 50 or $75 \mathrm{mg}$ of L-carnitine $/ \mathrm{kg}$ was included in the diets. L-carnitine could increase the fat content in breast muscles by decreasing the activity of carnitine palmitoyl transferase-I (CPT-I) (Velasco et al., 1997; 1998) and result in a lower rate of $\beta$-oxidation of fatty acids (Kudo et al., 1995; Winder \& Hardie, 1996; Velasco et al., 1997), thereby enhancing the fat content of muscles.

\section{Conclusions}

No significant interactions could be observed between L-carnitine and dietary energy density of broiler diets in terms of growth performance, some blood parameters and carcass traits of broiler chickens. The results of L-carnitine supplementation differed from the results obtained when a high ME diet was fed. High levels of ME significantly improved BWG and FCR without any significant changes in carcass composition of broiler chickens. It can be concluded that L-carnitine supplementation at different dietary densities of energy would have no additional benefits in terms of broiler growth and carcass quality. However, the effects 
of heat stress due to high ambient temperatures during the course of the experiment should be taken into consideration when interpreting these results.

\section{References}

AOAC, 1984. Official Methods of Analysis (14th ed.). Association of Official Analytical Chemists, Inc., Arlington, Virginia, USA.

Arab, H.A., Jamshidi, R., Rassouli, A., Shams, G. \& Hassanzadeh, M.H., 2006. Generation of hydroxyl radicals during ascites experimentally induced in broilers. Br. Poult. Sci. 47, 216-222.

Arslan, C., Citil, M. \& Saatci, M., 2004. Effects of L-carnitine administration on growth performance, carcass traits and some serum components of Japanese quail (Coturnix cot. japonica). Arch. Geflügelk. $68,111-114$.

Barker, D.L. \& Sell, J.L., 1994. Dietary carnitine did not influence performance and carcass composition of broiler chickens and young turkeys fed low- or high-fat diets. Poult. Sci. 73, 281-287.

Baumgartner, M. \& Blum, R., 1993. L-carnitine in animal nutrition. Pages 413-418 in vitamine und weitere zusatzstoffe bei mensch und tier (vitamins and other supplements for humans and animals). (G 5 . Flachowsky and R Schubert, editors). Friedrich-Schiller Universitaet, Jena, Germany.

Bremer, J., 1983. Carnitine metabolism and functions. Physiol. Rev. 63, 1420-1480.

Buyse, J., Janssens, G.P.J. \& Decuypere, E., 2001. The effects of dietary L-carnitine supplementation on the performance, organ weights and circulating hormone and metabolite concentrations of broiler chickens reared under a normal or low temperature schedule. Br. Poult. Sci. 42, 230-241.

Cahaner, A. \& Leenstra, F., 1992. Effects of high temperature on growth and efficiency of male and female broilers from lines selected for high weight gain, favourable food conversion and high or low fat content. Poult. Sci. 71, 1237-1250.

Cahaner, A., Deeb, N. \& Gutman, M., 1993. Effects of the plumage-reducing naked neck (Na) gene on the performance of fast growing broilers at normal and high ambient temperatures. Poult. Sci. 72, 767-775.

Cartwright, A.L., 1986. Effect of carnitine and dietary energy concentration on body weight and body lipid of growing broilers. Poult. Sci. 65 (Suppl. 1), 21-29.

Celik, L. \& Ozturkcan, O., 2003. Effects of dietary supplemental L-carnitine and ascorbic acid on performance, carcass composition and plasma L-carnitine concentration of broiler chicks reared under different temperature. Arch. Anim. Nutr. 57, 27-38.

Celik, L., Ozturkcan, O., Inal, T.C., Canacankatan, N. \& Kayrin, L., 2003. Effects of L-carnitine and niacin supplied by drinking water on fattening performance, carcass quality and plasma L-carnitine concentration of broiler chicks. Arch. Anim. Nutr. 57, 127-136.

Coles, E.H., 1986. Veterinary Clinical Pathology. 4th Ed. W.B. Saunders Company, Philadelphia, PA, USA.

Daskiran, M. \& Teeter, R.G., 2001. Effects of dietary L-carnitine (Carniking ${ }^{\mathbb{B}}$ ) supplementation on overall performance and carcass characteristics of seven-week-old broiler chickens. http://www.ansi.okstate.edu/research/2001rr/35/35.html. Accessed Aug. 2001.

Duncan, D.B., 1955. Multiple range test and multiple F tests. Biometrics 11, 1-42.

Eberhart, D.E. \& Washburn, K.W., 1993. Assessing the effect of naked neck gene on chronic heat stress resistance in 2 genetic stocks. Poult. Sci. 72, 1391-1399.

Elstner, E.F., 1991. Oxygen radicals-biochemical basis for their efficacy. Klinische Wochenschrift 69, 949956.

Feller, A.G. \& Rudman, D., 1988. Role of carnitine in human nutrition. J. Nutr. 118, 541-547.

Halliwell, B. \& Gutteridge, J.M.C., 1990. Role of free radicals and catalytic metal ions in human disease: an overview. Meth. Enzym. 186, 185-204.

Halliwell, B., Gutteridge, J.M.C. \& Cross, C.E., 1992. Free radicals, antioxidants and human disease; Where are we now? J. Lab. Clin. Med. 598-620.

Harmeyer, J., Schlumbohm, C. \& Baumgartner, M., 1998. Der gehalt an L-carnitin in futter- und lebensmitteln pflanzlicher und tierischer herkunft und der einfluss von herstellungsverfahren auf dessen gehalt (carnitine content in feed and food of vegetable and animal origin and the impact of processing on the content). In: Einfluss von erzeugung und verarbeitung auf die qualitat landwirtschaftlicher produkte, Ed VDLUFA Verlag, Darmstad, Germany. pp. 489-492. 
Izah, A.L., Colberg, M., Reiber, M.A., Adams, M.H., Skinner, J.T., Cabel, M.C., Stilborn, H.L. \&. Waldroup, P.W., 1990. Effects of different antibiotics on performance, processing characteristics, and parts yields of broiler chickens. Poult. Sci. 69, 1787-1791.

Kudo, N., Barr, A.J., Barr, R.L., Desai, S. \& Lopaschuk, G.D., 1995. High rates of fatty acid oxidation during reperfusion of ischemic hearts are associated with a decrease in malonyl-CoA levels due to an increase in 5' P-AMP-activated protein kinase inhibition of acetyl-CoA carboxylase. J. Biol. Chem. $270,17513-17520$.

Leibetseder, J., 1995. Studies of L-carnitine effects in poultry. Arch. Anim. Nutr. 48, 97-108.

Lettner, V.F., Zollitsch, W. \& Halbmayer, E., 1992. Einsatz von L-carnitin im Hühnermastfutter. Bodenkultur. 43, 161-167.

Lien, T.F. \& Horng, Y.M., 2001. The effect of supplementary dietary L-carnitine on the growth performance, serum components, carcase traits and enzyme activities in relation to fatty acid $\beta$ oxidation of broiler chickens. Br. Poult. Sci. 42, 92-95.

Matalliotakis, I., Koumantaki, Y., Evageliou, A., Matalliotakis, G., Goumenou, A. \& Koumantakis, E., 2000. L-carnitine levels in the seminal plasma of fertile and infertile men: correlation with sperm quality. Int. J. Fertil. 45, 236-240.

Neuman, S.L., Lin, T.L. \& Hester, P.Y., 2002. The effect of dietary carnitine on semen traits of white leghorn roosters. Poult. Sci. 81, 495-503.

Novotny, B.J., 1998. L-carnitine. What difference does it make? Symp. Proc. 15th Dec., Leuven, Belgium.

NRC, 1994. Nutrient Requirements of Poultry (9th ed.). National Academy Press, Washington D.C., USA.

Rabie, M.H. \& Szilagyi, M., 1998. Effects of L-carnitine supplementation of diets differing in energy levels on performance, abdominal fat content and yield and composition of edible meat of broilers. Br. J. Nutr. 80, 391-400.

Rabie, M.H., Szilagyi, M. \& Gippert, T., 1997a. Effects of dietary L-carnitine supplementation and protein level on performance and degree of meatness and fatness of broilers. Acta Biolog. Hung. 48, 221-239.

Rabie, M.H., Szilagyi, M., Gippert, T., Votisky, E. \& Gerendai, D., 1997b. Influence of dietary L-carnitine on performance and carcass quality of broiler chickens. Acta Biolog. Hung. 48 (2), 241-252.

Rebouche, C.J., 1991. Ascorbic acid and carnitine biosynthesis. Amer. J. Clin. Nutr. 54, 1147-1152.

Rebouche, C.J. \& Paulson D.J., 1986a. Carnitine metabolism and functions in humans. Ann. Rev. Nutr. 6, 41-66.

Rebouche, C.J. \& Paulson, D.J., 1986b. Carnitine. Ann. Rev. Biochem. 57, 261-283.

Rodehutscord, M., Timmler, R. \& Dieckmann, A., 2002. Effect of L-carnitine supplementation on utilisation of energy and protein in broiler chicken fed different dietary fat levels. Arch. Anim. Nutr. 56, 431-441.

Skinner, J.T., Cabel, M.C., Waldroup, A.L. \& Waldroup, P.W., 1993. Effect of abrupt multiple changes in dietary nutrient density on performance of broilers. J. Appl. Poult. Res. 2, 33-39.

SPSSWIN, 1994. SPSS for Windows 6.1.3. SPSSWIN, Istanbul, Turkey.

Velasco, G., Geelen, M.J.H. \& Guzman, M., 1997. Control of hepatic fatty acid oxidation by 5 P-AMPactivated protein kinase involves a malonyl-CoA-dependent and a malonyl CoA-independent mechanism. Arch. Biochem. Biophys. 337, 169-175.

Velasco, G., Pulgar, G.T., Carling, D. \& Guzman, M., 1998. Evidence that the AMP-activated protein kinase stimulates rat liver carnitine palmitoyltransferase I by phosphorylating cytoskeletal components. FEBS Lett. 439, 317-320.

Winder, W.W. \& Hardie, D.G., 1996. Inactivation of acetyl-CoAcarboxylase and activation of AMPactivated protein kinase in muscle during exercise. Am. J. Physiol. 270, E299-E304.

WPSA, 1989. European table of energy values for poultry feedstuffs (3rd ed.). WPSA Subcommittee, Beekbergen. The Netherlands.

Xu, Z.R., Wang, M.Q., Mao, H.X., Zhan, X.A. \& Hu, C.H., 2003. Effects of L-carnitine on growth performance, carcass composition and metabolism of lipids in male broilers. Poult. Sci. 82, 408-413.

Yalçın, S., Settar,P., Özkan, S. \& Cahaner, A., 1997. Comparative evaluation of 3 commercial broiler stocks in hot vs temperate climates. Poult. Sci. 76, 921-929. 